\title{
Does sexual orientation of bullying target influence bystander response?
}

Research Article

\author{
Patricia Meglich, Tracy Porter² and Nancy Day ${ }^{3}$ \\ University of Nebraska at Omaha \\ ${ }^{2}$ Cleaveland State University \\ 3University of Missouri - Kansas City
}

\begin{abstract}
The Bystander Intervention Model (BIM) is applied to explore how bystanders to workplace bullying assess situations and choose responses based on the (female) target's sexual orientation. We investigate how attitudes of homophobia and amnestic heterosexism (AH) affect these responses. Vignettes of workplace mistreatment against lesbian, female bisexuals, or female heterosexual targets were randomly presented to respondents, who were asked to assess the degree of "mistreatment" they perceive, their feelings of personal responsibility, and their anticipated responses. Analysis of covariance was used to analyze the data. Regardless of levels of homophobia or $\mathrm{AH}$, respondents report less active intervention when the target is lesbian compared to bisexual or heterosexual females. Respondents do not distinguish between conditions in clarity or severity of bullying. However, those higher in homophobia and $\mathrm{AH}$ feel less personal responsibility and are less likely to intervene when the target is lesbian.
\end{abstract}

Keywords: sexual orientation; lesbian; workplace bullying; bystander; intervention

(c) Sciendo

\section{INTRODUCTION}

Understanding and creating conditions that are welcoming and conducive to a wide range of workers can help to attract and retain high quality individuals in today's competitive environment. Interpersonal treatment is one aspect of the work environment that relates to many important work outcomes such as turnover, mental health, and stress (Lutgen-Sandvik et al., 2016). Workplace bullying, a persistent course of targeted abuse, is a well-researched type of mistreatment that affects many workers and leads to undesirable outcomes (Nielsen and Einarsen, 2012). Employees in the sexual minority (lesbian, gay, bisexual, and transgender - LGBT) report more harassment (EEOC, 2016; Hoel et al., 2017; Katz-Wise and Hyde, 2012) and status-based mistreatment (eg. bullying) (McCord et al., 2018) than their heterosexual counterparts. Yet, despite a robust and growing body of research on workplace bullying, the influence of the target's sexual orientation is an understudied aspect of the phenomenon.

Social dominance (Sidanius and Pratto, 1999) and stereotype (Blashill and Powlishta, 2009) theories have been used historically to explain abuse and mistreatment of those in the sexual minority. Dominant group members (heterosexual) may try to assert superiority over subservient groups (sexual minority) (Evans, 2017; Maclniss and Hodson, 2015; McCord et al., 2018). Likewise, individuals who violate gender role expectations (stereotyping) may be singled out for persecution (Bernstein et al., 2003; McCord et al., 2018). Thus, there is reason to consider how sexual orientation may influence workplace bullying. Sexual orientation, especially regarding lesbian, gay, or bisexual (LGB) workers (i.e. sexual minority), may be one determinant of bystanders' (witnesses) responses, yet little research has been conducted in this vein (Katz., et al., 2019).

Cited research throughout the paper refers to studies on various groups of individuals in the sexual minority. However, it is important to note there is not a consistent sub-grouping categorization scheme. While our specific research focus is lesbians and women bisexuals as targets, we report on other studies that included different 
segments of the sexual minority population and remain faithful to the nomenclature (e.g. LGBT, LGB, etc.) of prior research. Throughout our discussions we strive to be explicit about the exact population studied.

While our research is specifically focused on workplace bullying, we use the broader term "mistreatment" when it more accurately conveys previous research findings. We use "mistreatment" as an umbrella term that encompasses a range of interpersonal counterproductive work behavior including incivility, harassment, and abusive supervision (McCord et al., 2018).

Bystanders to bullying can validate the experience of a target and assist and support the target, making their role particularly important in addressing workplace bullying (Coyne et al., 2019). Exploring the response of bystanders to workplace bullying based on target sexual orientation may uncover effective strategies to reduce the detrimental effects of this type of mistreatment in a marginalized workforce segment (Mulder, et al., 2017; Paull, et al., 2012).

\section{Aims of the study}

There is a dearth of research in the organizational sciences relative to how and why a bystander to workplace bullying may respond based on the sexual orientation of the target. The primary aim of the current study is to explore this line of questioning with a specific focus on women targets.

Drawing from research in education and social psychology, we use the Bystander Intervention Model (BIM; Latané and Darley, 1970), which has not been tested in working adults (except in the context of cyberbullying in college students) (Brody and Vangelisti, 2016), as we wish to discover its applicability to workplace bullying. Further, we extend the BIM by including covariates of homophobia and amnestic heterosexism, discussed in the following sections. The proposed relationships are illustrated in Figure 1.

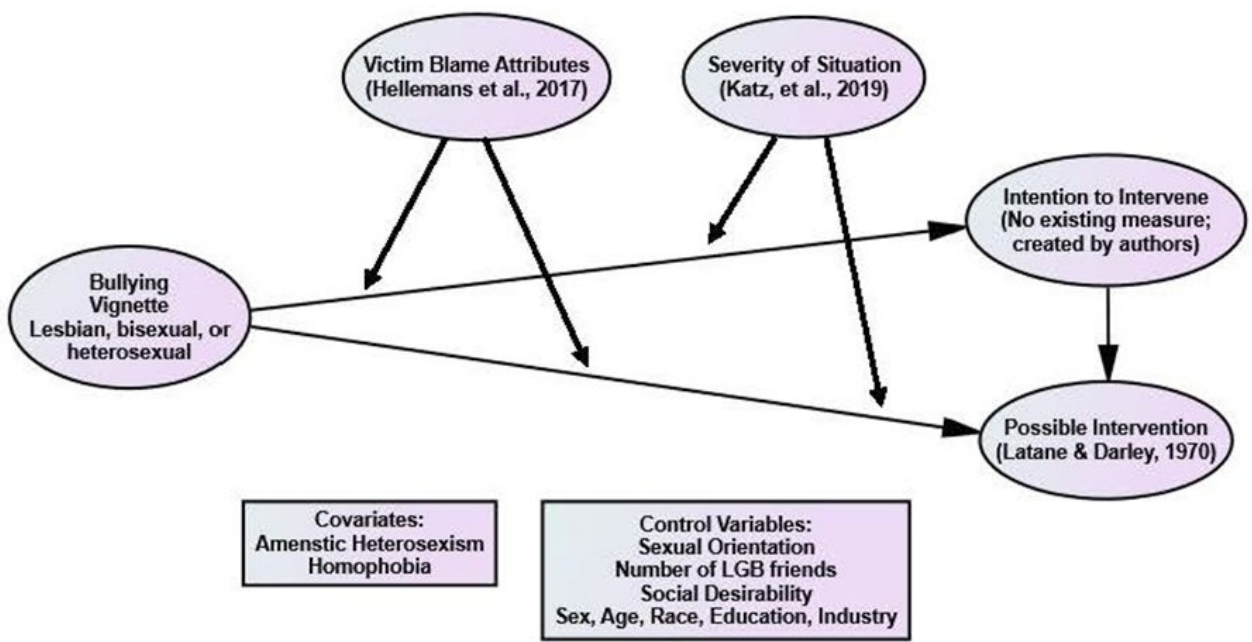

Figure 1. Proposed theoretical model

We agree with Worthen's (2013) compelling argument that research should distinguish among sexual minority groups, since lesbians and gay men experience workplace bullying differently (Salin and Hoel, 2013). To date, much of the research on sexual minority populations has failed to differentiate among these subgroups (Herek, 2002; Worthen, 2013), which risks overlooking important differences within these populations (Herek, 1994; KatzWise and Hyde, 2012; Maclnnis and Hodson, 2015). We address this deficiency by investigating three groups of women (lesbians, bisexuals, and heterosexuals) and thus avoid aggregating sexual minority individuals into a single category dubbed "LGB".

Female targets. We study female targets because they are often disadvantaged in many settings. Since most workplaces continue to be masculinized environments (Berdahl, et al., 2018), women occupy lower-impact jobs (DeSilver, 2018) and receive lower pay (Graf, et al., 2018), making them more vulnerable to mistreatment (Gates and Viggiani, 2013). Further, sexual minority women in particular may face situations of bullying at a higher rate than heterosexual women. Thus, our study of women who are targeted by bullies is framed by the theories 
of homophobia (fear of homosexuality; Fyfe, 1983; Herek, 1995) and amnestic heterosexism (belief that sexual minorities are not disadvantaged; Walls, 2008) as they help to explain why sexual orientation of the target may be a salient cue for bystander responses. We extend Katz et al.'s (2019) study of anti-gay (male) bullying to a different target population, women targets - lesbians, bisexuals, and heterosexuals.

Bisexual targets. Research on bisexuals is especially sparse (Corrington, et al., 2018) despite the fact that they constitute the largest reported segment of the LGBT population (Catalyst, 2017; Gallup, 2017). Perceptions of bisexual individuals are distinct from those of homosexual individuals and it has been suggested that attitudes towards each subgroup are unique constructs (Eliason, 1997). Thus, we explore the perception of bystanders regarding bullying of bisexual (females) as a specific subsample within the study. We offer research questions as there is insufficient previous research to allow us to formulate testable hypotheses about this segment of the sexual minority population.

\section{Bystander intervention}

Bystanders to emergencies, crises, and abuse may respond in ways that escalate or halt the situation. While bystander responses to crises and emergencies have been studied in violence/sexual assault (Chabot et al., 2018; Lukacena et al., 2019), medical emergency (Fischer et al., 2011), cyberbullying (Koehler and Weber, 2018), and school bullying settings (Jenkins and Nickerson, 2019), there is far less in the workplace bullying context (Mulder et al., 2016; Paull et al., 2012), especially related to target sexual orientation as an antecedant.

Noteworthy research on bystanders includes Hellemans et al.'s (2017) study that found the most common bystander responses to bullying were either passive or noninterventionist. MacCurtain et al.'s (2018) study of Irish nurses who witnessed bullying found that $64 \%$ adopted a low-involvement intervention (i.e. informally discuss the situation with colleagues or superior) while $9 \%$ did nothing in response. Bullying mode (online or offline), bullying type (personal or work-focused), and target-bystander relationship influenced bystander intentions to intervene in Coyne et al.'s (2019) cross-sectional study. Lastly, Mulder et al. (2014) found that bystander intervention was, in part, determined by ascribed responsibility for the bullying behavior. Other studies on bystanders have focused on the impact to themselves as witnesses. Negative consequences such as depression (Emdad et al., 2013) and stress (Vartia, 2001) have been reported.

The BIM (Latané and Darley, 1970) has been utilized in studies of sexual harassment (Nickerson et al., 2014), domestic violence (Hoefnagels and Zwikker, 2001), and emergencies (Darley et al, 1973). The BIM (Latané and Darley, 1970) progresses through five sequential stages that we situate within a workplace bullying context. First, the bystander must notice the event; thus, the process begins with awareness that bullying is occurring. Next, the bystander must interpret the event as an emergency requiring help; the bullying must be assessed and judged to be sufficiently harmful to the target. Third, the bystander accepts responsibility for intervening. No longer considered a disinterested third party, the bystander determines that s/he has a role to play in addressing the bullying. Next, the bystander must know what to do and how to intercede. This presumes that the bystander knows how to respond to apparent bullying. Finally, the bystander implements an intervention decision, choosing from various options.

Myriad factors have been shown to influence the bystander's propensity to act - gender (Poteat and Vecho, 2016), relationship/friendship with the target (Coyne et al., 2019; Ryan and Wessel, 2012; D'Cruz and Noranda, 2010), perceived severity of the incident (Koehler and Weber, 2018), attributed target responsibility (Mulder et al., 2014), empathy (Nickerson et al., 2014) and accomplices (Namie and Lutgen-Sandvik, 2010). Bystander responses to emergency situations are complex and involve cognitive, emotional, and behavioral components (Koehler and Weber, 2018). Additionally, the context of the situation may also play a part in influencing bystander perceptions and decisions.

\section{Ambiguity}

A contextual factor that has been shown to influence bystander responses to an emergency is the ambiguity or clarity of the situation (Nickerson et al., 2014). Extant research by Latane and Darley (1968) showed that the interpretation of an ambiguous situation (e.g. a smoke-filled room) to be an emergency was influenced by other witnesses to the event. In their study of alcohol-related sexual assault on college campuses, Pugh et al. (2016) found that the certainty of risk to a female victim was one element in determining bystanders' response to the situation. When bystanders determined that the situation constituted a clear, blatant emergency, they were more likely to intervene than when the victim did not appear to be in immediate danger. Observers of sexual orientation harassment were more likely to intercede when the perpetrator's intent to harm the target was unequivocal (Ryan 
and Wessel, 2012). The absence of strong, compelling signals to act may reduce bystander accountability in ambiguous situations (Latané and Darley, 1970). Therefore, the explicitness or ambiguity of an event may affect the bystander's subsequent decisions and actions.

\section{Homophobia and homophobic bullying}

Homophobia is a fear of homosexuality that often results in negative stereotypes and discrimination against those in the sexual minority (Fyfe, 1983; Herek, 1995). It is frequently associated with derogatory remarks and treatment of LGB individuals (Einarsdóttir et al., 2015; Hettinger and Vandello, 2014). The construct of homophobia is well explored and researched in the sociology and gender studies literatures with less attention focused on it in the organization sciences, particularly studies of the workplace (Eliason et al., 2011).

Homophobia is pervasive and can lead to mistreatment of individuals who are either openly homosexual or are perceived to be homosexual. For example, prejudice and discrimination in employment decisions are not uncommon, with $27 \%$ of LGB workers (Katz-Wise and Hyde, 2012) and 38\% of openly homosexual workers reporting experiencing at least one form of sexual orientation discrimination (Sears and Mallory, 2011). Studies of selective incivility provide further evidence that sexual minority workers are subjected to higher levels of workplace incivility than their heterosexual counterparts (Zurbrügg and Miner, 2016).

\section{Amnestic heterosexism}

Amnestic heterosexism (AH) is the belief that individuals in the sexual minority are no longer subjected to discrimination related to their sexual orientation (Katz et al., 2019). Derived from the term 'amnesia,' individuals who hold AH beliefs may deny that LGB people face discrimination or unfair treatment because of sexual minorities' perceived progress in advancing their rights (Thorpe, 2017). In other words, these individuals have "forgotten" that LGB individuals were once mistreated and now presume that there is no ongoing issue. This leads them to dismiss the existence of sexual orientation discrimination. On its surface, this may seem counterintuitive, but is understandable based on cognitive dissonance theory (Festinger, 1962; Katz, et al., 2019). Those who believe LGB individuals are now on an "equal playing field" with heterosexuals may experience cognitive dissonance when they witness LGB-focused discrimination. Since they believe this type of discrimination no longer exists, they resolve their cognitive dissonance by removing themselves from the situation - in bystanders' case, by refusing to intervene or blaming the victim. Thus, witnesses higher in $\mathrm{AH}$ will be less likely to see themselves responsible for intervention, or to intervene in the bullying.

Indeed, $\mathrm{AH}$ has been shown to mediate the relationship between support for gay rights and 'belief in a just world' (i.e. people get what they deserve; Hettinger and Vandello, 2014). Notably, Katz et al. (2019) found that those higher in $\mathrm{AH}$ felt lower levels of responsibility to intervene in bullying directed at gay men. $\mathrm{AH}$ is therefore a potential explanatory variable in understanding why bystanders to a workplace bullying incident may refrain from interceding, since they would not view the situation as mistreatment or harmful.

We believe that these two attitudes, homophobia and $\mathrm{AH}$, will affect how bystanders respond to witnessing an ambiguous workplace situation involving women of various sexual orientations. We study these dynamics in the context of the BIM (Latané and Darley, 1970). The first stage of the BIM is awareness that bullying is happening. Since this awareness is presented in our experimental manipulation, we begin our first set of hypotheses with the BIM's second stage, interpreting the behavior as bullying.

Note that we refer to "mistreatment" in our hypotheses, as this is the term we used in research materials seen by participants. We did not use the term "bullying" in research materials, since "bullying" is now a commonly used and emotionally charged word that may trigger certain responses; we desired participants to respond to the behavior without automatically defining it as "bullying" to avoid the possibility of priming specific responses. For clarity, we continued this word choice in the method and analyses sections.

Hypothesis 1: Bystanders' attitudes towards sexual minority females will predict whether they interpret ambiguous negative behavior as mistreatment. Specifically:

H1a: Bystanders high in homophobia will be less likely to interpret ambiguous negative behavior as mistreatment and harmful when the target is lesbian and more likely to interpret ambiguous negative behaviors as mistreatment and harmful when the target is heterosexual. 
H1b: Bystanders high in AH will be less likely to interpret ambiguous negative behavior as mistreatment and harmful when the target is lesbian and more likely to interpret ambiguous negative behaviors as mistreatment and harmful when the target is heterosexual.

As noted above, the lack of research on bisexuals prevents us from making specific predictions about this subsample. Thus, we test research questions related to each hypothesis.

Research question 1: How will bystanders' attitudes towards bisexuals predict whether they interpret ambiguous negative behavior as bullying?

We now address later stages of the BIM, beginning with accepting responsibility for intervening (stage three). The precursor to taking any action is embracing the responsibility to act. Diffusion of responsibility is an enduring obstacle (Beyer et al., 2017) as the number of other bystanders is a powerful influence on felt responsibility (Cox and Adam, 2018; Katz and Klainberg, 2019). Considerable research has shown that as the number of additional bystanders increases, the felt responsibility for a lone bystander diminishes (the so-called 'bystander effect').

Accepting responsibility to intervene may also be influenced by the severity of the situation (Hellemans et al., 2017), the bystander's gender (e.g. female) (Bennett et al., 2017), and the relationship with the target and/or perpetrator (Palmer et al., 2018). In-group targets of violence were more likely to be helped by bystanders than outgroup targets in experimental research conducted in the U.K. (Levine et al., 2002). Considering that sexual minority targets of mistreatment would be more likely considered as out-group individuals, we predict the following:

Hypothesis 2: Bystanders' attitudes toward sexual minority females will predict their intention to intervene when faced with ambiguous negative behavior. Specifically:

H2a: When faced with ambiguous negative behavior, bystanders high in homophobia will be less likely to feel they have personal responsibility to intervene when the target is lesbian and more likely to feel they have personal responsibility to intervene when the target is heterosexual.

$H 2 b$ : When faced with ambiguous negative behavior, bystanders high in AH will be less likely to feel they have personal responsibility to intervene when the target is lesbian and more likely to feel they have personal responsibility to intervene when the target is heterosexual.

Research question 2: When faced with ambiguous negative behavior, how will bystanders' attitudes towards bisexuals predict whether they feel personal responsibility to intervene?

Lastly, we address the final (fifth) stage of the BIM, the type of intervention decision. (We omit testing the fourth stage, knowing what to do to intervene; since we limited participants to full-time employed adults 25 or over, we assume they will be familiar with normal workplace interventions). Intervention alternatives include more and less assertive responses. The bystander might choose to directly confront the perpetrator, a more assertive option, or indirectly intercede by reporting the situation to someone in authority, a less assertive response. Limited prior research could be located that specifically focused on the assertiveness of the bystander's response choice.

Bystander intention to intervene assertively may be influenced by the potential costs incurred as a result. Ryan and Wessel (2012) found that observers of workplace sexual orientation harassment were influenced by the possibility that failure to intervene would lead to a generalized hostile work environment that would also impact their working conditions. As detailed in the arousal-cost-reward model (Piliavin et al., 1975), bystanders weigh the costs of helping against those of not helping and then act such that their own net costs are minimized (Fritzsche et al., 2000). Thus, we predict that the intervention chosen will reflect minimal cost to the bystander.

Hypothesis 3: Bystanders' attitudes toward sexual minority females will predict their reported level of intended interventions when faced with ambiguous negative behavior. Specifically,

H3a: Bystanders high in homophobia will report an intention to take less active interventions when the target is lesbian and to take more active interventions when the target is heterosexual. 
$H 3 b$ : Bystanders high in $\mathrm{AH}$ will report an intention to take less active interventions when the target is lesbian and to take more active interventions when the target is heterosexual.

Research question 3: When faced with ambiguous negative behavior, how will bystanders' attitudes toward bisexuals predict how actively they report they would intervene?

\section{METHOD}

Our study is an experimental design using "vignettes," or short descriptions of a workplace event, as examples of bullying presented randomly as occurring to either a lesbian, female bisexual, or female heterosexual target. We used a pre-test to develop these vignettes and test the experimental manipulation before the actual the study that tested the hypotheses. Approval for the pre-test and final study was obtained from one of the authors' university's Institutional Review Board (a federally regulated committee responsible for ensuring ethics in human subject research in the U.S.).

\section{Pre-test}

The pre-test was designed to identify vignettes and ensure the effectiveness of the experimental manipulation of the target's sexual orientation. Vignettes were developed by first referring to Escartin et al.'s (2009) identification of bullying behavior severity. Our goal was to choose vignettes that were ambiguous enough to require respondents to evaluate event severity; extreme examples of bullying would elicit clear, socially expected responses, which would not allow us to test our hypotheses adequately. We chose "manipulating information," "abusive working conditions," and "professional discredit," all of which were ranked as the "middle level" of severity, and developed four vignettes illustrating examples of these behaviors (see Appendix A). We constructed vignettes to match the definition of bullying: they include behaviors that offend, exclude, or negatively affect the target's work and are repeated and regular (Zapf et al., 2002). The pre-test utilized 50 Mturk respondents (Amazon's online data collection methodology). The sexual orientation of the target ("Susan") was manipulated by describing her as dating "Thomas" (heterosexual condition), "Maria" (lesbian condition), or "Maria and Thomas" (bisexual condition) as well as clearly stating Susan's orientation (the manipulation can be found in Appendix A). The pre-test respondents identified Susan's correct sexual orientation 81 percent of the time.

The pre-test also identified two vignettes used for the study, based on participants' responses to two questions: "how clearly does this vignette represent workplace mistreatment" and "how harmful does Terry's behavior in the vignette seem?" We chose vignettes based on these criteria: 1) vignettes rated as most ambiguous (those whose means were closest to the middle of the four item scale); vignettes whose interpretations were most variable (those whose standard deviations were largest). The vignettes chosen are labeled \#1 and \#2 in Appendix A.

\section{Study: Effect of target's sexual orientation on bystander responses to bullying}

We randomly presented respondents with one of the three sexual orientations and they read and reacted to the two vignettes. Since responses to both vignettes represented each person's typical bystander reactions and intentions, we combined each respondent's data across the two vignettes for all analyses.

Clarity and harmfulness of mistreatment (hypothesis 1) were measured identically to the pre-test (one item each; Katz et al., 2019). We operationalized intention to intervene (hypothesis 2 ) by using personal responsibility to help, as measured by Fischer et al.'s (2006) four-item scale (sample item: "I feel personally responsible for helping Susan in this situation"; $\alpha=.95)$.

The level of intended intervention (hypothesis 3) was adapted by using nine items from Salmivalli, et al.'s (1996) study of school bullying; Nickerson, et al. (2014) adapted these items in a similar fashion. Three items each represented behaviors 1) defending the target (sample item: "I would tell Terry I'm going to tell George about his behavior toward Susan"), 2) sympathizing with the target (sample item: I would make a point to spend more time with Susan"), and 3) avoiding the problem (sample item: "I would stay out of it"). Because of our sample size, we wanted to reduce scale dimensions where possible, thus we factor analyzed type of intervention (maximum likelihood, varimax rotation), resulting in two clear factors (accounting for 48 percent of the variance) that emerged for each vignette: avoidance (three items; $\alpha=.88$ ) and intervention (six items, $\alpha=.88$ ). 
Homophobia was measured by Raja and Stokes' (1998) seven-item Homophobia Scale (sample item: "Homosexuals are just as moral as heterosexuals"; $\alpha=.94)$. AH was measured using the four items from the Multidimensional Heterosexism Inventory's AH subscale (Walls, 2008) (sample item: "Most people treat lesbians as fair as they treat everyone else"; $\alpha=.93$ ).

The sample for the study was obtained through Mturk, Amazon's online data collection methodology. Although online data collection methodologies are growing in acceptance, it remains important to carefully manage this type of data collection to ensure validity of responses. A frequent concern is that "professional responders" will participate in multiple surveys as soon as they are available (Walter et al., 2016). To determine if this dynamic occurred in our data, we divided the adult sample into four equal groups based on order of submission and compared the dependent variables' means. Finding no pattern of differences between "first responders" and later responders, we eliminated order effect as a threat to validity. We also set the software $\left(\right.$ Qualtrics $\left.^{\circledR}\right)$ to reject multiple responses from the same respondent and ensured respondents' time to complete the survey was adequate. Following new research indicating that attention checks (designed to ensure participants do not mindlessly check boxes) are detrimental to online studies (Vanette, 2017), we opted instead for asking respondents to agree they would thoughtfully answer each question. In both data collections, only U.S. adults (age 25 or over) who were employed full-time (at least 30 hours a week) were eligible.

After eliminating 35 respondents for missing data or failing the manipulation check, 168 respondents were available for Study 2 . Their average age was 33 , with a minimum of 25 and maximum of 90 . Most were male (62 percent); a very small number (3 respondents) reported they were transgender or "other." The majority were heterosexual ( 80 percent), with 16 percent reporting being bisexual, one person reported being a gay man, two respondents being lesbians, and one reported being "queer/questioning."

\section{RESULTS}

Descriptive statistics and the correlation matrix are available in Table 1. Overall, our three hypotheses predict that respondents higher in homophobia and $\mathrm{AH}$ will be less likely to identify mistreatment, interpret it as mistreatment and harmful, and show intentions to respond when the target is lesbian versus heterosexual.

Table 1. Descriptive statistics and correlations

\begin{tabular}{|c|c|c|c|c|c|c|c|c|c|c|c|c|c|}
\hline & & Mean & $\begin{array}{l}\text { Standard } \\
\text { Deviation }\end{array}$ & $\alpha$ & 1 & 2 & 3 & 4 & 5 & 6 & 7 & 8 & 9 \\
\hline 1 & $\operatorname{Sex}^{1}$ & - & - & - & 1.00 & & & & & & & & \\
\hline 2 & White/Persons of Color ${ }^{2}$ & - & - & - & -0.01 & 1.00 & & & & & & & \\
\hline 3 & Age & 33.00 & 8.80 & - & 0.11 & -0.12 & 1.00 & & & & & & \\
\hline 4 & $\begin{array}{l}\text { Clearly Represents } \\
\text { Mistreatment }\end{array}$ & 2.85 & 0.76 & 0.64 & $0.17^{\star}$ & -0.09 & -0.03 & 1.00 & & & & & \\
\hline 5 & How Harmful Is Behavior & 5.75 & 2.2 & 0.72 & $0.17^{*}$ & 0.02 & -0.07 & $0.77^{\star *}$ & 1.00 & & & & \\
\hline 6 & Personal Responsibility & 4.96 & 2.55 & 0.95 & $0.24^{\star \star}$ & -0.02 & -0.09 & $0.67^{\star \star}$ & $0.80^{\star *}$ & 1.00 & & & \\
\hline 7 & Avoidance & 2.81 & 1.03 & 0.88 & -0.03 & $0.31^{\star \star}$ & -0.09 & $-0.20^{*}$ & -0.08 & $-0.29 * \star$ & 1.00 & & \\
\hline 8 & Active Intervention & 3.21 & 0.83 & 0.88 & $0.17^{*}$ & -0.03 & $-0.21^{\star \star}$ & $0.49 * \star$ & $0.55^{\star \star}$ & $0.72 * \star$ & $-0.23^{\star \star}$ & 1.00 & \\
\hline 9 & Homophobia & 2.56 & 1.52 & 0.94 & 0.01 & $0.17^{\star}$ & -0.02 & -0.04 & 0.02 & 0.01 & $0.40 * \star$ & 0.08 & 1.00 \\
\hline 10 & Amnestic Heterosexism & 3.24 & 1.55 & 0.93 & -0.11 & 0.07 & -0.04 & -0.10 & 0.00 & -0.04 & $0.43^{\star \star}$ & 0.01 & $0.55^{\star \star}$ \\
\hline
\end{tabular}

We use analysis of covariance and multivariate analysis of covariance similarly to stepwise regression (SPSS's ${ }^{\circledR}$ General Linear Model). Because we seek to test differences between categorical groups (target sexual orientation), regression analysis is a less appropriate method than analysis of variance. We first test simple mean differences across conditions (Table 2). Our subsequent analyses (Tables 3 through 5 ) enter homophobia and AH into each equation as covariates to determine if the significance of any mean differences changes after controlling for these 
attitudes. Since we are particularly interested in whether bystanders interpret negative behaviors differently if the target is a sexual minority (lesbian or bisexual), analysis of variance allows us to use the heterosexual condition as the comparison group.

Main effects can be found in Table 2, which shows that the only dependent variable that differs significantly across sexual orientation conditions is active intervention. Post hoc analyses show respondents report lower likelihood to actively intervene when the target is lesbian as compared to heterosexual. No other mean differences are seen.

\section{Hypothesis 1}

Hypothesis 1 predicts that respondents who are higher in homophobia (1a) or AH (1b) will be less likely to interpret a lesbian target's experience as clearly mistreatment (operationalized as bullying) and less likely to see it harmful than they will the heterosexual target's experiences. Although as Table 2 (below) indicates no significant differences are seen between the conditions on either dependent variable, including homophobia or $\mathrm{AH}$ as covariates (thus

Table 2. Main effects: Mean differences between sexual orientations

\begin{tabular}{|c|c|c|c|c|c|c|}
\hline Dependent Variable & & $\mathbf{N}$ & Mean & $\begin{array}{c}\text { Std. } \\
\text { Deviation }\end{array}$ & $\mathbf{F}$ & $\rho$ \\
\hline \multicolumn{7}{|c|}{ Houe loorly Rohovior lo Mictreatment } \\
\hline & Bisexual & 56 & 2.95 & 0.76 & & \\
\hline & Heterosexual & 55 & 2.84 & 0.73 & & \\
\hline & Total & 167 & 2.85 & 0.76 & 0.786 & 0.458 \\
\hline \multirow[t]{4}{*}{ How Harmful Is Behavior } & Lesbian & 56 & 5.44 & 2.21 & & \\
\hline & Bisexual & 56 & 5.96 & 2.10 & & \\
\hline & Heterosexual & 55 & 5.79 & 2.30 & & \\
\hline & Total & 167 & 5.73 & 2.20 & 0.831 & 0.437 \\
\hline \multirow[t]{4}{*}{ Personal Responsibility } & Lesbian & 56 & 4.30 & 2.56 & & \\
\hline & Bisexual & 56 & 5.25 & 2.44 & & \\
\hline & Heterosexual & 55 & 5.28 & 2.56 & & \\
\hline & Total & 167 & 4.94 & 2.55 & 2.747 & 0.067 \\
\hline \multirow[t]{4}{*}{ Avoidance } & Lesbian & 56 & 2.67 & 1.03 & & \\
\hline & Bisexual & 56 & 2.85 & 1.06 & & \\
\hline & Heterosexual & 55 & 2.92 & 1.02 & & \\
\hline & Total & 167 & 2.81 & 1.04 & 0.865 & 0.423 \\
\hline \multirow[t]{4}{*}{ Active Intervention } & Lesbian & 56 & 2.98 & 0.90 & & \\
\hline & Bisexual & 56 & 3.25 & 0.71 & & \\
\hline & Heterosexual & 55 & 3.38 & 0.82 & & \\
\hline & Total & 167 & 3.20 & 0.83 & 3.541 & 0.031 \\
\hline
\end{tabular}


controlling for them) does not change these results, as can be seen in Table 3. Regardless of whether the target is lesbian or heterosexual, respondents higher in homophobia do not differ in how clearly the behavior represents mistreatment $(\rho=.562)$ or how harmful it is $(\rho=.410)$. Similarly, respondents higher in AH also do not distinguish between these two variables based on sexual orientation (clarity, $\rho=.433$; harmfulness, $\rho=.396$ ). Thus, neither hypothesis $1 \mathrm{a}$ nor $1 \mathrm{~b}$ is supported.

Research question 1 explores if respondents will interpret behavior differently if the target is bisexual as compared to heterosexual. Table 3 also shows these results. Regardless of their levels of homophobia or AH, our respondents do not distinguish between bisexuals and heterosexuals in the clarity or harmfulness of negative behavior.

Table 3. Hypothesis 1: Homophobia and amnestic heterosexism as covariates to clarity and harmfulness of behavior

\begin{tabular}{|c|c|c|c|c|c|c|c|c|}
\hline & & \multicolumn{2}{|c|}{$\begin{array}{c}\text { Overall Mean } \\
\text { Differences }\end{array}$} & \multicolumn{5}{|c|}{ Group Comparisons } \\
\hline & & $\mathbf{F}$ & Sig. $F$. & $\mathbf{B}$ & Std. Error & $\mathbf{t}$ & $\rho$ & Partial $\eta_{2}$ \\
\hline \multicolumn{9}{|c|}{ Hypothesis 1a: Homophobia as Covariate } \\
\hline \multirow{3}{*}{$\begin{array}{l}\text { How Clearly Behavior } \\
\text { Is Mistreatment }\end{array}$} & Intercept & 619.164 & 0.000 & 2.91 & 0.15 & 18.96 & 0.000 & 0.69 \\
\hline & Susan's Sexual Orientation & 0.857 & 0.426 & & & & & 0.01 \\
\hline & Condition: Lesbian & & & -0.09 & 0.15 & -0.58 & 0.562 & 0.00 \\
\hline \multirow{9}{*}{$\begin{array}{l}\text { How Harmful Is } \\
\text { Behavior }\end{array}$} & Condition: Bisexual & & & 0.10 & 0.15 & 0.72 & 0.475 & 0.00 \\
\hline & Condition: Heterosexual & & & \multicolumn{5}{|c|}{ (Comparison group) } \\
\hline & Homophobia & 0.378 & 0.540 & -0.02 & 0.04 & -0.61 & 0.540 & 0.00 \\
\hline & Intercept & 284.749 & 0.000 & 5.79 & 0.44 & 13.02 & 0.000 & 0.51 \\
\hline & Susan's Sexual Orientation & 0.806 & 0.448 & & & & & 0.01 \\
\hline & Condition: Lesbian & & & -0.35 & 0.43 & -0.83 & 0.410 & 0.00 \\
\hline & Condition: Bisexual & & & 0.17 & 0.42 & 0.41 & 0.680 & 0.00 \\
\hline & Condition: Heterosexual & & & \multicolumn{5}{|c|}{ (Comparison group) } \\
\hline & Homophobia & 0.000 & 0.991 & 0.00 & 0.12 & 0.01 & 0.991 & 0.00 \\
\hline \multicolumn{9}{|c|}{ Hypothesis 1b: Amnestic Heterosexism as Covariate } \\
\hline \multirow{3}{*}{$\begin{array}{l}\text { How Clearly Behavior } \\
\text { Is Mistreatment }\end{array}$} & Intercept & 469.404 & 0.000 & 3.04 & 0.18 & 16.98 & 0.000 & 0.64 \\
\hline & Susan's Sexual Orientation & 0.882 & 0.416 & & & & & 0.01 \\
\hline & Condition: Lesbian & & & -0.12 & 0.15 & -0.79 & 0.433 & 0.00 \\
\hline \multirow{9}{*}{$\begin{array}{l}\text { How Harmful Is } \\
\text { Behavior }\end{array}$} & Condition: Bisexual & & & 0.07 & 0.15 & 0.50 & 0.619 & 0.00 \\
\hline & Condition: Heterosexual & & & \multicolumn{5}{|c|}{ (Comparison group) } \\
\hline & Amnestic Heterosexism & 1.958 & 0.164 & -0.05 & 0.04 & -1.40 & 0.164 & 0.01 \\
\hline & Intercept & 201.543 & 0.000 & 5.85 & 0.52 & 11.20 & 0.000 & 0.44 \\
\hline & Susan's Sexual Orientation & 0.835 & 0.436 & & & & & 0.01 \\
\hline & Condition: Lesbian & & & -0.37 & 0.43 & -0.85 & 0.396 & 0.00 \\
\hline & Condition: Bisexual & & & 0.16 & 0.43 & 0.38 & 0.703 & 0.00 \\
\hline & Condition: Heterosexual & & & \multicolumn{5}{|c|}{ (Comparison group) } \\
\hline & Amnestic Heterosexism & 0.018 & 0.893 & -0.02 & 0.11 & -0.13 & 0.893 & 0.00 \\
\hline
\end{tabular}

\section{Hypothesis 2}

Hypothesis 2 explores if homophobia (2a) or AH (2b) affect intention to intervene, as measured by feelings of personal responsibility toward the target. Our analysis of main effects (Table 2, above) illustrates that personal responsibility differs across the target's sexual orientation at a less-than-significant level $(\rho=.067)$. Including homophobia as a covariate, however, shows more homophobic respondents tend to feel less personal responsibility when the target of mistreatment is lesbian (Table $4 ; \rho=.041$ ). The same result is shown for hypothesis $2 \mathrm{~b}$ : respondents higher in $\mathrm{AH}$ tend feel less personal responsibility when the target of mistreatment is lesbian (Table $4, \rho=.027$ ). Thus, hypothesis 2 is supported. 
Table 4. Hypothesis 2: Homophobia and amnestic heterosexism as covariates to personal responsibility

\begin{tabular}{|c|c|c|c|c|c|c|c|c|}
\hline & & \multicolumn{2}{|c|}{$\begin{array}{l}\text { Overall Mean } \\
\text { Differences }\end{array}$} & \multicolumn{5}{|c|}{ Group Comparisons } \\
\hline & & $\mathbf{F}$ & Sig. $F$. & B & Std. Error & $\mathbf{t}$ & $\rho$ & Partial $\eta 2$ \\
\hline \multicolumn{9}{|c|}{ Hypothesis 2a: Homophobia as Covariate } \\
\hline \multirow{6}{*}{ Personal Responsibility } & Intercept & 167.697 & 0.000 & 5.38 & 0.51 & 10.57 & 0.000 & 0.41 \\
\hline & Susan's Sexual Orientation & 2.746 & 0.067 & & & & & 0.03 \\
\hline & Condition: Lesbian & & & -1.01 & 0.49 & -2.06 & 0.041 & 0.03 \\
\hline & Condition: Bisexual & & & -0.04 & 0.48 & -0.09 & 0.930 & 0.00 \\
\hline & Condition: Heterosexual & & & \multicolumn{5}{|c|}{ (Comparison group) } \\
\hline & Homophobia & 0.062 & 0.804 & -0.03 & 0.13 & -0.25 & 0.804 & 0.00 \\
\hline \multicolumn{9}{|c|}{ Hypothesis 2b: Amnestic Heterosexism as Covariate } \\
\hline \multirow{6}{*}{ Personal Responsibility } & Intercept & 133.588 & 0.000 & 5.78 & 0.60 & 9.70 & 0.000 & 0.37 \\
\hline & Susan's Sexual Orientation & 3.083 & 0.048 & & & & & 0.04 \\
\hline & Condition: Lesbian & & & -1.10 & 0.49 & -2.24 & 0.027 & 0.03 \\
\hline & Condition: Bisexual & & & -0.12 & 0.49 & -0.25 & 0.801 & 0.00 \\
\hline & Condition: Heterosexual & & & \multicolumn{5}{|c|}{ (Comparison group) } \\
\hline & Amnestic Heterosexism & 1.011 & 0.316 & -0.13 & 0.13 & -1.01 & 0.316 & 0.01 \\
\hline
\end{tabular}

Research question 2 explores this same dynamic regarding bisexual targets. As can be seen in Table 4, respondents higher in homophobia or $\mathrm{AH}$ did not differ in their feelings of personal responsibility based on whether the target was heterosexual or bisexual ( $\rho=.930$ and $\rho=.801$, respectively).

\section{Hypothesis 3}

Hypothesis 3 predicts that respondents who are higher in homophobia (3a) and $\mathrm{AH}(3 \mathrm{~b})$ will be less likely to intend to actively intervene in mistreatment when the target is lesbian. As discussed, we measured intervention in two dimensions: avoidance and active intervention intentions. As noted above (Table 2), no differences between the target's sexual orientations are seen in avoidance $(\rho=.423)$, but overall, respondents report significantly lower intentions for active interventions when the target is lesbian as compared to heterosexual $(\rho=.031)$. Investigating this relationship in the context of our covariates, we find that respondents higher in homophobia do not differ in intentions to avoid intervention for lesbian targets $(\rho=.728)$, but they do report lower intentions to actively intervene when targets are lesbian $(\rho=.015)$.

Repeating these analyses with $\mathrm{AH}$ as the covariate similarly does not reveal higher avoidance intention for lesbian targets (Table $5, \rho=.999$ ), but does show a tendency for less active intervention for lesbian as compared to heterosexual targets $(\rho=.009)$. Thus, hypothesis 3 is partially supported.

The third research question investigates these relationships when targets are bisexual. Our results show that respondents higher in either homophobia or $\mathrm{AH}$ do not distinguish between heterosexuals and bisexuals in terms of their invention intentions, either to avoid or to intervene ( $\rho=.429$ and $\rho=.368$, respectively).

\section{Post-hoc considerations: Social desirability bias}

In reviewing our data post-hoc, an analysis of variance of homophobia and $\mathrm{AH}$ across sexual orientation conditions revealed significant differences - surprising given that random assignment should equalize all personal characteristics across conditions. The only reasonable conclusion is that mere assignment to the sexual minority condition created a social desirability bias; knowing the target of bullying was a sexual minority lowered responses to the homophobia and $\mathrm{AH}$ scales. Compared to respondents whose target was heterosexual, respondents whose target was lesbian were significantly lower in homophobia $(\rho<.039)$ and $\mathrm{AH}(\rho<.008)$ and those whose target was bisexual was significantly lower in $\mathrm{AH}(\rho<.050)$. On reflection, this is not unexpected, since contemporary U.S. employers emphasize acceptance of diverse sexual orientations. Thus, knowing the target is lesbian or bisexual seems to encourage the desire to "look good"; given these results, it is surprising that some of our hypotheses were supported, as the effects of homophobia and $\mathrm{AH}$ seem to have been artificially attenuated. 
Table 5. Hypothesis 3: Homophobia and amnestic heterosexism as covariates to avoidance and active intervention

\begin{tabular}{|c|c|c|c|c|c|c|c|c|}
\hline & & \multicolumn{2}{|c|}{$\begin{array}{l}\text { Overall Mean } \\
\text { Differences }\end{array}$} & \multicolumn{5}{|c|}{ Group Comparisons } \\
\hline & & $\mathbf{F}$ & Sig. $\mathbf{F}$ & $\mathbf{B}$ & Std. Error & $\mathbf{t}$ & $\rho$ & Partial $\eta 2$ \\
\hline \multicolumn{9}{|c|}{ Hypothesis 3a: Homophobia as Covariate } \\
\hline & Intercept & 209.03 & 0.000 & 2.16 & 0.19 & 11.16 & 0.000 & 0.43 \\
\hline \multirow[t]{6}{*}{ Avoidance } & Susan's Sexual Orientation & 0.08 & 0.927 & & & & & 0.00 \\
\hline & Condition: Lesbian & & & -0.06 & 0.19 & -0.35 & 0.728 & 0.00 \\
\hline & Condition: Bisexual & & & 0.00 & 0.18 & -0.02 & 0.981 & 0.00 \\
\hline & Condition: Heterosexual & & & \multicolumn{5}{|c|}{ (Comparison group) } \\
\hline & Homophobia & 28.33 & 0.000 & 0.27 & 0.05 & 5.32 & 0.000 & 0.15 \\
\hline & Intercept & 629.63 & 0.000 & 3.32 & 0.16 & 20.19 & 0.000 & 0.71 \\
\hline \multirow[t]{5}{*}{ Active Intervention } & Susan's Sexual Orientation & 3.14 & 0.046 & & & & & 0.04 \\
\hline & Condition: Lesbian & & & -0.39 & 0.16 & -2.45 & 0.015 & 0.04 \\
\hline & Condition: Bisexual & & & -0.12 & 0.16 & -0.79 & 0.429 & 0.00 \\
\hline & Condition: Heterosexual & & & \multicolumn{5}{|c|}{ (Comparison group) } \\
\hline & Homophobia & 0.27 & 0.606 & 0.02 & 0.04 & 0.52 & 0.606 & 0.00 \\
\hline \multicolumn{9}{|c|}{ Hypothesis 3b: Amestic Heterosexism as Covariate } \\
\hline & Intercept & 116.65 & 0.000 & 1.84 & 0.22 & 8.24 & 0.000 & 0.29 \\
\hline \multirow[t]{6}{*}{ Avoidance } & Susan's Sexual Orientation & 0.31 & 0.735 & & & & & 0.00 \\
\hline & Condition: Lesbian & & & 0.00 & 0.18 & 0.00 & 0.999 & 0.00 \\
\hline & Condition: Bisexual & & & 0.12 & 0.18 & 0.67 & 0.505 & 0.00 \\
\hline & Condition: Heterosexual & & & \multicolumn{5}{|c|}{ (Comparison group) } \\
\hline & Amnestic Heterosexism & 34.66 & 0.000 & 0.29 & 0.05 & 5.89 & 0.000 & 0.18 \\
\hline & Intercept & 471.32 & 0.000 & 3.46 & 0.19 & 17.91 & 0.000 & 0.66 \\
\hline \multirow[t]{5}{*}{ Active Intervention } & Susan's Sexual Orientation & 3.63 & 0.029 & & & & & 0.04 \\
\hline & Condition: Lesbian & & & -0.42 & 0.16 & -2.63 & 0.009 & 0.04 \\
\hline & Condition: Bisexual & & & -0.14 & 0.16 & -0.90 & 0.368 & 0.00 \\
\hline & Condition: Heterosexual & & & \multicolumn{5}{|c|}{ (Comparison group) } \\
\hline & Amnestic Heterosexism & & & -0.02 & 0.04 & -0.47 & 0.640 & 0.00 \\
\hline
\end{tabular}

\section{DISCUSSION}

The central premise of this study was to investigate six initial hypotheses which focused on vignettes presenting incidents of workplace bullying. Respondents were randomly assigned to vignettes that differed based on the sexual orientation of the target and asked to determine their potential reaction to the situation. The findings make several important contributions to the literature. First, the study extends the research around the BIM (Latane and Darley, 1970) by applying it to an adult population, specifically, a subset of the LGB sexual minority group (e.g. lesbian and female bisexuals). Second, we demonstrate factors that might influence when an individual would avoid or ignore a bullying situation and when they might actively participate and mitigate bullying; we also show that these responses differ based on the target's sexual orientation. Third, we add to the research on the relatively new construct of $\mathrm{AH}$ and show that it is predictive of important outcomes related to bystander behavior.

One of our goals was to assess the applicability of the BIM (Latane and Darley, 1970) to workplace bullying. The results of this study suggest that the stages of the model are relevant and applicable to workplace bullying scenarios. The BIM states individuals who witness bullying go through five stages, the first being recognition that bullying is occurring. Within this research we focused on the second (interpret event as bullying), third (accept responsibility to help), and fifth (deciding to intervene) stages of the model to gain insight into sexual minority 
bullying. We found that the sexual orientation of a bullying target had no effect on respondents' interpretation of an ambiguous negative event as clearly bullying (presented to respondents as the broader term, "mistreatment") or harmful. Thus, bystanders seem to view the actual behavior objectively; negative behavior is seen as negative regardless of to whom it is directed.

We did find that respondents' level of homophobia or AH impacts how personally responsible they feel about intervening in a bullying situation when the target is lesbian: the more homophobic or $\mathrm{AH}$ a respondent was, the less inclined they were to feel a responsibility to act. These findings support previous research that recognizes LGBT individuals report higher levels of harassment (EEOC 2016; Hoel et al., 2017; Katz-Wise and Hyde, 2012) and that women suffer from more sex-based mistreatment (McCord et al., 2018). Our results bolster the findings from Katz et al.'s (2019) study of amnestic heterosexism and the bullying of gay men by extending their work to the bullying of lesbians. If bystanders feel less personal responsibility to help lesbians, bullying is more likely to occur.

In terms of active intervention, regardless of their homophobia or $\mathrm{AH}$, all respondents reported less inclination to intervene when the target is lesbian. However, homophobia and AH seem to exacerbate this relationship.

It is interesting to note that none of our research questions regarding bisexuals showed any significant findings. Respondents did not differ in interpreting the event, taking responsibility for action, or intervening when the target was bisexual compared to heterosexual. Neither homophobia nor AH changed these results. This suggests that female bisexuals are seen more similarly to female heterosexuals in situations of bullying. As Worthen (2013) noted, studying subgroups within the LGB community is critical, and this is underscored by our findings; combining lesbians and female bisexuals into a "sexual minority" category would have obscured these results. Thus, ours is a preliminary finding in parsing out differences between sexual minority subgroups, which is important, as experiences of and attitudes toward gay men, lesbians, and bisexuals probably differ in the workplace.

\section{Practical implications}

These findings are of value to organizational leaders for a number of reasons. The literature clearly demonstrates the challenging experiences of those in the sexual minority with respect to workplace treatment. Our research demonstrates the organizational "roadblocks" which might be in place and offers leaders a lens into where they might focus their anti-bullying training protocols. For example, as respondents did not differ in their interpretation of a bullying event based on the sexual orientation of the target, negative behaviors seem to be interpreted similarly, regardless of the target. However, when it came to their feelings of personal responsibility to act on behalf of the target, respondents higher in homophobia or AH felt less responsible when the target was lesbian. This is important for organizational leaders to understand, recognize, and address before bullying happens within their company. It suggests that heightening respect and understanding of sexual minorities is important in motivating bystanders to help targets of bullying; interventions such as affinity group interactions, "safe space" training, or other diversity education may increase feelings of personal responsibility for action against bullying regardless of sexual orientation.

Finally, organizational leaders should recognize that bystanders of bullying may actively intervene less often when the target is a sexual minority, particularly when bystanders hold homophobic or amnestic heterosexist attitudes. Leaders should consider ways to mitigate instances where a sexual minority employee might be bullied at work and determine how to encourage bystanders to intercede.

\section{Contributions, limitations, and future research}

We believe this study contributes to the literature in several ways. First, it applies the BIM, a model frequently found in studies of non-work-based settings, to the workplace. This has been done only rarely in past research. We also show that the bystander experience is appropriately framed by this model.

Second, we separated sexual minority subgroups (lesbians and female bisexuals), consequently finding different results. This is an advance in the very small body of literature that addresses bisexuals as a group different from other sexual minorities and worthy of study.

Third, we show that lesbian targets of bullying are indeed viewed differently by bystanders, and that bystanders themselves differ in their propensity to intervene. We found that bystanders who are more homophobic and amnestic heterosexist are less likely to take personal responsibility or actively intervene when they witness lesbian bullying targets. Thus, we show that these variables are important attitudes that are predictive of bystander responses to the bullying of sexual minorities. 
The contributions of this research should be considered in light of the limitations. For example, though we originally sought to collect data which would offer a sufficient sample size, this did not prove to be the case. As can be seen, the partial $\eta^{2}$ s for many of the equations were low, ranging from below .01 (no effect) to .04 (a medium effect). Unfortunately, resources did not allow for a larger sample size, which we believe would have bolstered our results. Given that even with low power we saw significant and meaningful findings, larger sample sizes are warranted.

A further weakness is that our study presents "paper people" to respondents. They did not view real-life interactions. A laboratory study using videos of vignettes would be a more externally valid research design.

Future research should, along with an increase in sample size, apply a more robust research design to mitigate potential issues with social desirability bias. While we designed the questionnaire so that respondents were exposed to the vignettes first, and then the attitudes (so that attitudes would not influence their bystander responses), clearly this is a less than optimal design. A better design would be to create a time gap between the measure of bystander reactions and attitudes, which would necessitate surveying the same respondents twice, in two different waves. Our past experience, and that of most researchers, is that this requires significant investment in sample size (due to Wave 2 dropouts). Unfortunately, given the time and budget constraints of our study this was not possible.

\section{CONCLUSION}

Although not without limitations, this study paves the way for future research in this arena. The significant results we found, even in light of social desirability bias and power issues, show that bystanders to bullying will respond differently based on the sexual orientation of the target. This finding adds to an extremely small body of literature and thus makes a significant contribution to the study of bullying as well as attitudes toward sexual minority females.

\section{References}

Bennett, S., Banyard, V.L. and Edwards, K.M. (2017). 'The impact of the bystander's relationship with the victim and the perpetrator on intent to help in situations involving sexual violence.' Journal of Interpersonal Violence, 32: 5, 682-702.

Berdahl, J.L., Cooper, M., Glick, P., Livingston, R W. and Williams, J.C. (2018). 'Work as a masculinity contest.' Journal of Social Issues, 74: 3, 422-448.

Bernstein, M., Kostelac, C. and Gaarder, E. (2003). "Understanding "heterosexism": Applying theories of racial prejudice to homophobia using data from a southwestern police department.' Race, Gender, \& Class, 10: 4, 54-74.

Beyer, F., Sidarus, N., Bonicalzi, S. and Haggard, P. (2017). 'Beyond self-serving bias: diffusion of responsibility reduces sense of agency and outcome monitoring.' Social Cognitive \& Affective Neuroscience, 12: 1, 138-145.

Blashill, A. and Powlishta, K. (2009). 'Gay stereotypes: The use of sexual orientation as a cue for genderrelated attributes.' Sex Roles, 61: 11-12, 783-793.

Brody, N. and Vangelisti, A.L. (2016). 'Bystander intervention in cyberbullying.' Communication Monographs, 83: 1, 94-119.

Catalyst. (2017, May 30). 'Lesbian, gay, bisexual, and transgender workplace issues.' Online: http:// www.catalyst.org/knowledge/lesbian-gay-bisexualtransgender-workplace-issues.

Chabot, H.F., Gray, M.L., Makande, T.B. and Hoyt, R.L. (2018). 'Beyond sex: Likelihood and predictors of effective and ineffective intervention in intimate partner violence in bystanders perceiving an emergency.' Journal of Interpersonal Violence, 33: 12, 1909-1930.

Corrington, A., Nittrouer, C.L., Trump-Steele, R.C.E. and Hebl, M. (2018). 'Letting him B: A study on the intersection of gender and sexual orientation in the workplace.' Journal of Vocational Behavior, online October 10. Online: doi.org/10.1016/j. jvb.2018.10.005.

Cox, A. and Adam, A. (2018). 'The bystander effect in non-emergency situations: Influence of gender and group size.' Modern Psychological Studies, 23: 2, 1-14.

Coyne, I., Gopaul, A.-M., Campbell, M., Pankász, A., Garland, R., and Cousans, F. (2019). 'Bystander Responses to Bullying at Work: The Role of Mode, Type and Relationship to Target'. Journal of Business Ethics, 157(3), 813-827. https://doi-org. leo.lib.unomaha.edu/10.1007/s10551-017-3692-2.

Darley, J. M., Teger, A. I., and Lewis, L. D. (1973). 'Do groups always inhibit individuals' responses to 
potential emergencies?' Journal of Personality and Social Psychology, 26:3, 395-399.

D'Cruz, P. and Noronha, E. (2010). 'The limits to workplace friendship.' Employee Relations, 33:3, 269-288.

DeSilver, D. (2018). 'Women scarce at the top of U.S. business - and in the jobs that lead there.' FactTank: News in the Numbers, Pew Research Center. Online: https://www.pewresearch.org/ fact-tank/2018/04/30/women-scarce-at-top-of-u-sbusiness-and-in-the-jobs-that-lead-there/.

EEOC. (2016). Select Task Force on the Study of Harassment in the Workplace: Report of CoChairs Chai R. Feldblum \& Victoria A. Lipnic. Online: https://www.eeoc.gov/eeoc/task_force/ harassment/report.cfm.

Eliason, M.J. (1997). 'The prevalence and nature of biphobia in heterosexual undergraduate students.' Archives of Sexual Behavior, 26, 317-326.

Eliason, M.J., Dibble, S. and Robertson, P. (2011). 'Lesbian, gay, bisexual, and transgender (LGBT) physicians' experiences in the workplace.' Journal of Homosexuality, 58: 10, 1355-1371.

Emdad, R., Alipour, A., Hagberg, J. and Jensen, I.B. (2013). 'The impact of bystanding to workplace bullying on symptoms of depression among women and men in industry in Swededn: An empirical and theoretical longitudinal study.' International Archives of Occupational and Environmental Health, 86:6, 709-716.

Einarsdottir, A., Hoel, H., Lewis, D. (2015). 'It's nothing personal': Anti-homosexuality in the British workplace.' Sociology, 49:6, 1183-1199.

Escartín, J., Rodríguez-Carballeira, A., Zapf, D., Porrúa, C. and Martín-Peñaa, J. (2009). 'Perceived severity of various bullying behaviours at work and the relevance of exposure to bullying.' Work \& Stress, 23: 3, 191-205.

Evans, D. (2017). 'Categorizing the magnitude and frequency of exposure to uncivil behaviors: A new approach for more meaningful interventions.' Journal of Nursing Scholarship, 49: 2, 214-222.

Festinger, L. (1962). A Theory of Cognitive Dissonance. Stanford, CA: Stanford University Press.

Fischer, P., Greitemeyer, T., Pollozek, F. and Frey, D. (2006). 'The unresponsive bystander: Are bystanders more responsive in dangerous emergencies?' European Journal of Social Psychology, 36: 2, 267-278.

Fischer, P., Krueger, J.I., Greitemeyer, T., Kastenmüller, A., Heene, M., Wicher, M. and Kainbacher, M. (2011). 'The bystander-effect: A meta-analytic review on bystander intervention in dangerous and non-dangerous emergencies.' Psychological Bulletin, 137: 4, 517-537.

Fritzsche, B.A., Finkelstein, M.A. and Penner, L.A. (2000). 'To help or not to help: Capturing individuals' decision policies.' Social Behavior \& Personality: An International Journal, 28: 6, 561-578.

Fyfe, B. (1983). "Homophobia" or homosexual bias reconsidered.' Archives of Sexual Behavior, 12: 6, 549-554.

Gallup. (2017, January 11). 'In U.S., more adults identifying as LGBT.' Online: http://news.gallup. com/poll/201731/lgbt-identification-rises.aspx.

Gates, T.G. and Viggiani, P.A. (2013). 'Understanding lesbian, gay, and bisexual worker stigmatization: A review of the literature.' International Journal of Sociology and Social Policy, 34: 5/6, 359-374.

Graf, N., Brown, A. and Patten, E. (2018). 'The narrowing, but persistent, gender gap in pay.' FactTank: News in the Numbers: Pew Research Center. Online: http://www.pewresearch.org/fact-tank/2018/04/09/ gender-pay-gap-facts/.

Hellemans, C., Dal Cason, D. and Casini, A. (2017). 'Bystander helping behavior in response to workplace bullying.' Swiss Journal of Psychology, 76: 4, 135-144.

Herek, G.M. (1994). 'Assessing attitudes toward lesbians and gay men: A review of empirical research with the ATLG scale', in B. Greene and G.M. Herek (eds), Lesbian and Gay Psychology, Thousand Oaks, CA: Sage.

Herek, G.M. (1995). 'Psychological heterosexism in the United States', in A.R. D'Augelli and C.J. Patterson (eds), Lesbian, Gay, and Bisexual Identities Over the Lifespan: Psychological Perspectives, New York: Oxford University Press.

Herek, G.M. (2002). Heterosexuals' attitudes toward bisexual men and women in the United States. The Journal of Sex Research, 39: 4, 264-275.

Hettinger, V. and Vandello, J. (2014). 'Balance without equality: Just world beliefs, the gay affluence myth, and support for gay rights.' Social Justice Research, 27: 4, 444-463.

Hoefnagels, C. and Zwikker, M. (2001). 'The bystander dilemma and child abuse: Extending the Latané and Darley model to domestic violence.' Journal of Applied Social Psychology, 31:6, 1158-1183.

Hoel, H., Lewis, D. and Einarsdottir, A. (2017). 'Debate: Bullying and harassment of lesbians, gay men and bisexual employees: Findings from a representative British national study.' Public Money \& Management, 37: 5, 312-314.

Jenkins, L.N. and Nickerson, A.B. (2019). 'Bystander intervention in bullying: Role of social skills and 
gender.' Journal of Early Adolescence, 39: 2, 141166.

Katz, J., Federici, D. and Ramos-Dries, T. (2019). 'Amnestic heterosexism and bystander responses to anti-gay bullying.' Journal of Homosexuality, 66 : 1, 1-16.

Katz, J. and Klainberg, S. (2019). 'Effects of group status and implicit theories of personality on bystander responses to antigay bullying.' Psi Chi Journal of Psychological Research, 24, 97-105.

Katz-Wise, S.L. and Hyde, J.S. (2012). 'Victimization experiences of lesbian, gay, and bisexual individuals: A meta-analysis.' Journal of Sex Research, 49: 2-3, 142-167.

Koehler, C. and Weber, M. (2018). "'Do I really need to help?!" Perceived severity of cyberbullying, victim blaming, and bystanders' willingness to help the victim.' Cyberpsychology, 12: 4, 1-15.

Latané, B. and Darley, J.M. (1968). 'Group inhibition of bystander intervention in emergencies.' Journal of Personality and Social Psychology, 10: 3, 215-221.

Latané, B. and Darley, J.M. (1970). The Unresponsive Bystander: Why Doesn't He Help? Englewood Cliffs, NJ: Prentice Hall.

Levine, M., Cassidy, C., Brazier, G. and Reicher, S. (2002). 'Self-categorization and bystander nonintervention: Two experimental studies.' Journal of Applied Social Psychology, 32: 7, 1452-1463.

Lukacena, K.M., Reynolds-Tylus, T. and Quick, B.L. (2019). 'An application of the reasoned action approach to bystander intervention for sexual assault.' Health Communication, 34: 1, 46-53.

Lutgen-Sandvik, P., Hood, J. N. and Jacobson, R. P. (2016). 'The impact of positive organizational phenomena and workplace bullying on individual outcomes'. Journal of Managerial Issues, 28:1-2, 30-49.

MacCurtain, S., Murphy, C., O'Sullivan, M., MacMahon, J. and Tuerner, T. (2018). 'To stand back or step in? Exploring the responses of employees who observe workplace bullying.' Nursing Inquiry, 25(1).

Maclnnis, C.C. and Hodson, G. (2015). 'Why are heterosexual men (vs. women) particularly prejudiced toward gay men? A social dominance theory explanation.' Psychology \& Sexuality, 6: 3, 275-294.

McCord, M.A., Dhanani, L.Y., Joseph, D.L. and Beus, J.M. (2018). 'A meta-analysis of sex and race differences in perceived workplace mistreatment.' Journal of Applied Psychology, 103: 2, 137-163.

Mulder, R., Bos, A.E.R., Pouwelse, M. and van Dam, K. (2017). 'Workplace mobbing: How the victim's coping behavior influences bystander responses.' Journal of Social Psychology, 157: 1, 16-29.
Mulder, R., Pouwelse, M., Lodewijkx, H., Bos, A.E.R. and van Dam, K. (2016). 'Predictors of antisocial and prosocial behaviour of bystanders in workplace mobbing.' Journal of Community \& Applied Social Psychology, 26: 3, 207-220.

Mulder, R., Pouwelse, M., Lodewijkx, H. and Bolman, C. (2014). 'Workplace mobbing and bystanders' helping behaviour towards victims: The role of gender, perceived responsibility and anticipated stigma by association.' International Journal of Psychology, 49:4, 304-312.

Namie, G. and Lutgen-Sandvik, P.E. (2010). 'Active and passive accomplices: The communal character of workplace bullying.' International Journal of Communication, 4, 343-373.

Nickerson, A.B., Aloe, A.M., Livingston, J.A. and Feeley, T.H. (2014). 'Measurement of the bystander intervention model for bullying and sexual harassment.' Journal of Adolescence, 37: 4, 391-400.

Nielsen, M. and Einarsen, S. (2012). 'Outcomes of exposure to workplace bullying: A meta-analytic review.' Work and Stress, 26:4, 309-332.

Palmer, J.E., Nicksa, S.C. and McMahon, S. (2018). 'Does who you know affect how you act? The impact of relationships on bystander intervention in interpersonal violence situations.' Journal of Interpersonal Violence, 33: 17, 2623-2642.

Paull, M., Omari, M. and Standen, P. (2012). 'When is a bystander not a bystander? A typology of the roles of bystanders in workplace bullying.' Asia Pacific Journal of Human Resources, 50: 3, 351-366.

Piliavin, I.M., Piliavin, J.A. and Rodin, J. (1975). 'Costs, diffusion, and the stigmatized victim.' Journal of Personality and Social Psychology, 32, 429-438.

Poteat, V.P. and Vecho, O. (2016). 'Who intervenes against homophobic behavior? Attributes that distinguish active bystanders.' Journal of School Psychology, 54, 17-28.

Pugh, B., Ningard, H., Ven, T.V. and Butler, L. (2016). 'Victim ambiguity: bystander intervention and sexual assault in the college drinking scene.' Deviant Behavior, 37: 4, 401-418.

Raja, S. and Stokes, J.P. (1998). 'Assessing attitudes toward lesbians and gay men: The modern homophobia scale.' Journal of Gay, Lesbian, and Bisexual Identity, 3: 2, 113-134.

Ryan, A.M. and Wessel, J.L. (2012). 'Sexual orientation harassment in the workplace: When do observers intervene?' Journal of Organizational Behavior, 33: 4, 488-509.

Salin, D. and Hoel, H. (2013). 'Workplace bullying as a gendered phenomenon.' Journal of Managerial Psychology, 28: 3, 235-251. 
Salmivalli, C., Lagerspetz, K., Bjorkqvist, K., Osterman, K. and Kaukiainen, A. (1996). 'Bullying as a group process: Participant roles and their relations to social status within the group.' Aggressive Behavior, i: 1, 1-15.

Sears, B. and Mallory, C. (2011). Documented Evidence of Employment Discrimination \& Its Effects on LGBT People'. University of California, UCLA School of Law - Williams Institute. Online: https://williamsinstitute.law.ucla.edu/research/ discrimination/documented-evidence-ofemployment-discrimination-its-effects-on-lgbtpeople/.

Sidanius, J. and Pratto, F. (1999). Social Dominance. Cambridge, England: Cambridge University Press.

Thorpe, J.R. (2017). .People don't step in when they see anti-gay bullying for this sad reason, according to a new study. Bustle. Online https://www.bustle. $\mathrm{com} / \mathrm{p} /$ people-dont-step-in-when-they-see-antigay-bullying-for-this-sad-reason-according-to-anew-study-2991694.

Vanette, D. (2017). 'Using attention checks in your surveys may harm data quality.' QulatricsXM Blog. Online: https://www.qualtrics.com/blog/usingattention-checks-in-your-surveys-may-harm-dataquality.

Vartia, MA-L. (2001). 'Consequences of workplace bullying with respect to the well-being of its targets and the observers of bullying.' Scandinavian Journal of Work and Environmental Health, 27:1, 63-69.

Walls, N. (2008). 'Toward a Multidimensional understanding of heterosexism: The changing nature of prejudice,' Journal of Homosexuality, 55:1, 20-70.

Walter, S., Seibert, S., Goering, D.D. and O'Boyle, E.H. (2016). 'An Examination of the convergence of online panel data and conventionally sourced data.' Paper presented at the Academy of Management Annual Conference, Anaheim, CA.

Worthen, M. (2013). 'An argument for separate analyses of attitudes toward lesbian, gay, bisexual men, bisexual women, MtF and FtM transgender individuals.' Sex Roles, 68: 11-12, 703-723.

Zapf, D., Einarsen, S., Hoel, H., and Vartia, M. (2002). 'Empirical findings on bullying in the workplace,' in S. Einarsen, H. Hoel, and C. Cooper (eds), Bullying and Emotional Abuse in the Workplace: International Perspectives in Research and Practice, London: Taylor \& Francix.

Zurbrügg, L. and Miner, K.N. (2016). 'Gender, sexual orientation, and workplace incivility: Who is most targeted and who is most harmed?' Frontiers in Psychology, 7, 565. 


\section{APPENDIX A}

\section{Bullying vignettes used in study 1 (pre-test)}

We are interested in what you think about the following vignettes in terms of 1) how relevant they are to bullying; 2) how real they seem; 3) how severe they are. Please read about Susan then respond to each vignette. Here is what you need to know about Susan:

- Susan has been an administrative assistant at Acme Corporation for three years.

- Her supervisor is George, and generally, they get along well.

- $\quad$ She enjoys her job and gets good performance reviews.

- However, she does not like working with Terry, another administrative assistant in her department.

- Susan is heterosexual (lesbian, bisexual), 35 years old, single, has no children, and is in a very happy relationship with her boyfriend, Michael (. . . with her girlfriend Maria; . . . her girlfriend Maria and her boyfriend Michael).

\section{Vignette 1: Constantly remind him/her of any mistakes}

Susan was about to tackle the agenda for an important meeting when she saw Terry come around the corner and head towards her desk.

Terry leaned over and looked at what she's working on and said, "Oh man, I hope you don't screw that up like you did the one for the last meeting. What a mess that was, and George was so mad at you."

Susan frowned. This was about the fourth time Terry had said something like that about her work. Hoping Terry would just walk away, she turned her chair back to her computer screen and tried to focus on the agenda.

\section{Vignette 2: Treat with disdain his/her correct decisions and achievements}

Yesterday at the staff meeting, George complimented Susan on the report she had recently finished formatting. "It looked great. So easy to read and attractive. l'd like you to save that template and share it with other administrative assistants at Acme. It really makes our reports look professional."

Susan smiled and glanced around the room. Terry was sitting at an angle out of George's site. She saw Terry's eyes roll and Terry nudge the person sitting beside.

Susan hadn't expected Terry to approve of their boss's compliment to her, but she felt her stomach sink and looked down at her hands. Terry always seemed to be trying to belittle her work.

Vignette 3: Ensure that he/she is responsible for performing tasks with possible negative consequences At a recent staff meeting (including Susan and her co-worker? Terry), George, Susan's supervisor announced that a notoriously unpleasant hard-to-please client would be visiting and one of the administrative assistants would be required to facilitate the day's logistics and take notes. Susan remembers the last time this client came - he complained loudly throughout the session about the quality of event space they were in, as well as the food - even the level of detail in the agenda!

Later that day George thanked her for volunteering to take on this project. She was surprised, since she and Terry hadn't yet discussed it. Obviously, without her knowledge, Terry had told George that Susan had volunteered! She smiled and said, "You're welcome, George," inwardly fuming that Terry would do this kind of thing - again!

Vignette 4: Try to obstruct his/her work and control the information that he/she transmits to others George was rushing to an important meeting with the CEO of Acme. Susan handed him the report he'd asked her to prepare. As he skimmed through it, he looked up and frowned, asking, "Where is the section on the new product line? Terry said he told you I needed it! He said you were the one who'd taken charge of that. I've got to have it for this meeting! Get it to me in five minutes!" He sped out of the office at top speed.

Susan had no time to tell him that that was the first she'd heard about it. She scowled. Yet again, Terry hadn't told her something important she needed to do her job well. She tried not to panic as she started to prepare the document. 